\title{
Antimicrobial drug susceptibility of Staphylococcus aureus from subclinical bovine mastitis in Coimbatore, Tamilnadu, South India
}

\author{
H Muhamed Mubarack ${ }^{1}$, A Doss $^{1}$, M Vijayasanthi $^{1}$, R Venkataswamy $^{2}$
}

1. Department of Microbiology, RVS College of Arts and Science, Coimbatore - 641402 , India

2. Department of Pharmacognosy, Sri Ramakrishna College of Pharmaceutical Sciences, Coimbatore, Tamilnadu, South India

Corresponding author: $\mathrm{H}$ Muhamed Mubarack email: mubarack@rvsgroup.com

Received: 20-12-2011, Accepted: 02-01-2012, Published Online: 10-03-2012 doi: $10.5455 /$ vetworld.2012.352-355

\begin{abstract}
Aim: The study was carried out to investigate the prevalence and antimicrobial susceptibility of clinical pathogens isolated from Bovine Mastitis in and around Coimbatore District, Tamilnadu, South India.

Materials and Methods: A total of 250 milk samples were screened and 152 isolates of Staphylococci were obtained and their susceptibility to several antimicrobial agents by agar disc diffusion method.

Results: Out of 152 isolates of Staphylococcus aureus resistance was detected in 63 (41.44\%), 39 (25.65\%), 21(13.81\%), 18 $(11.84 \%), 6(3.94 \%)$ and $5(3.28 \%)$ isolates for penicillin, streptomycin, erythromycin, tetracycline, ampicillin and Cephalothin, respectively. No resistance was detected for Gentamicin.

Conclusion: Results indicated that these isolates exhibited the highest degree of resistance to penicillin of all antimicrobial agents tested.

Key words: Antimicrobial agents, Bovine Mastitis, Disc diffusion, Mastitis pathogens

To cite this article: Mubarack HM, Doss A, Vijayasanthi M, Venkataswamy R (2012) Antimicrobial Drug Susceptibility of Staphylococcus aureus from Subclinical Bovine Mastitis in Coimbatore, Tamilnadu, South India, Vet World 5(6): 352-355, doi: 10.5455/vetworld.2012.352-355
\end{abstract}

\section{I ntroduction}

Mastitis in bovines has become extremely complex and the costliest disease in India. It affects $50 \%$ of the herd population. It has been estimated that the mastitis alone can cause approximately $70 \%$ of all avoidable losses incurred during milk production [1]. It is incriminated as an important disease constraint in dairy cow and is responsible for reduction in quality and quantity of milk and milk products mainly due to microorganisms [2]. Over 135 different microorganisms have been isolated from bovine intramammary infections (IMI), but the majority of infections are caused by staphylococci, streptococci, and gram-negative bacteria [3]. As a remedy antimicrobials are used very frequently for infectious diseases on dairy farms, but the therapeutic outcome of S. aureus causing disease is poor, in part due to the versatile ability of the pathogen. Therefore, selection of a more effective drug for mastitis therapy by the evaluation of antimicrobial resistance may become a reality to clinical veterinarians [4].

Antibacterial therapy is an important part of a mastitis control program in dairy cattle [5]. In vitro antimicrobial sensitivity test of clinical or subclinical mastitis pathogens are frequently used by bovine practitioners to guide cow or herd level treatment decisions. However, for certain antimicrobial agents, previous studies failed to demonstrate statistically significant associations between the results of susceptibility testing and the treatment outcomes for clinical and/or subclinical mastitis [6]. Increased resistance of staphylococcal isolates recovered from mastitic domestic ruminants to different antimicrobial agents has been reported by several authors [7]. Antibiotics are routinely administered at drying-off to treat sub clinical cases of mastitis and prevent further infection [8]. Although fairly successful, this practice may lead to the development of antibiotic resistant strains, as reported for S.aureus [9]. Antibiotic treatment of mastitis leads to significant increase in milk quantity and quality, lower somatic cell count and is likely associated with reduction in prevalence of clinical mastitis among herds, which is economically beneficial [10]. Bacterial identification and susceptibility tests are important for selecting the appropriate antimicrobial agent when treating mastitis [11]. The purpose of this study was to determine the in vitro 
activity of antimicrobial drugs against S.aureus from subclinical cases of mastitis in Coimbatore district, Tamilnadu, South India.

\section{Materials and methods}

Animals: The whole study was conducted at Department of Microbiology, RVS College of Arts and Science, Sulur, Coimbatore, Tamilnadu during the period from May to November 2009. The lactating cows of the dairy farms of the Coimbatore Region have been examined from dairy herds in different small holder farms as well as large scale farms. Random number of sampling method has been used while selecting the cows in the farms visited.

Sampling: From May 2009 to April, 2010, a total of 250 raw milk samples were obtained from the dairy cows with clinical or sub-clinical bovine mastitis in small and large holders of Coimbatore District, Tamilnadu, India. Samples were collected aseptically for bacteriological studies as suggested by standard methods. Prior to sampling, the first streams of milk were discarded, and teat ends were disinfected with cotton swabs soaked in $70 \%$ alcohol and allowed to dry. The milk samples were transported on ice to the laboratory of the Post Graduate Department of Microbiology, RVS College of Arts and Science, Sulur, Coimbatore, Tamilnadu for further analysis.

I solation and I dentification of microorganisms from milk samples: Tenfold serial dilution of samples was made up to $10^{-6}$ in Nutrient broth (Becton Dickinson Ltd, USA, and BBL®) and Mac Conkey broth (Fluka Biochemika, Spain). Samples were plated in duplicate using pour plate technique. $0.5 \mathrm{ml}$ of the diluted sample was delivered by pipette into $19.5 \mathrm{ml}$ of enriched agar. Plates were incubated inverted in an incubator at $37^{\circ} \mathrm{C}$ for $24-48 \mathrm{~h}$. Total viable counts (aerobic mesophiles) were carried out on nutrient agar (Fluka Biochemika, Spain), Plate count agar (Oxoid, England), Trypticase soy agar and Soybean casein digest agar (Becton Dickinson Ltd, USA). The number of colony forming units (CFU) per milliliter were counted and recorded after appropriate incubation periods on plates with a visible colony range of 20-100. Quantitative analysis for the presence or absence of specific microorganisms was done by plating on selective media. Salmonella colonies on mannitol salt agar (Becton Dickinson Ltd, USA) were purified on Mac Conkey agar or Salmonella Shigella agar (SS-agar) (Fluka Biochemika India). Coliform count was done on Mac Conkey agar and Eosin Methylene Blue agar (International Diagnostic Group
Plc, UK). Counts were also made on mannitol salt agar (Baird Parker Medium, Merck, Germany) and cetrimide agar (Merck, Germany). Confirmatory biochemical and serological tests were performed on purified colonies. Carbohydrate studies and Indole test were done in peptone water (International Diagnostic Group Plc, UK).

Identification was based on growth on selective agar and broth, colony morphology, Gram's reaction, biochemical test results and criteria for disregarding negative cultures. Results were analyzed using Cowan and Steel Manual, and other methods for the identification of Medical Bacteria [12, 13, 14].

Antibiotic sensitivity profile: Antibiotic sensitivity screening of the bacterial organisms was analyzed for seven different antimicrobials namely Penicillin (10units), Streptomycin (10mcg), Erythromycin (15mcg), Tetracycline (30mcg), Gentamycin (10mcg), Ampicillin (30mcg), and Cephalothin (30 mcg).

Disc Diffusion (Bauer-Kirby) Susceptibility test: The modified disc diffusion method of Bauer et al. [15] was employed and the interpretation was made as per the interpretation chart provided by the manufacturer of discs depending on the diameter of zone of inhibition of bacterial growth. The disc diffusion test was done for each isolate on MuellerHinton agar (Hi-media). $20 \mathrm{ml}$ of medium was poured into $90 \mathrm{~mm}$ diameter sterile Petri dishes to a depth of 4 mm on a level surface to make the depth of the medium uniform and left at $37^{\circ} \mathrm{C}$ temperature overnight to check sterility.

Preparation of I noculum for Disc diffusion test: For inoculum's preparation $5 \mathrm{ml}$ tryptic soya broth (Himedia) was dispensed in screw capped tubes and sterilized by autoclaving at $121^{\circ} \mathrm{C}$ for 15 minutes. The tubes were cooled and kept in an incubator for 24 hours at $35^{\circ} \mathrm{C}$ to check sterility. Each isolate was inoculated in the sterilized tubes containing the medium, and placed in an incubator overnight at $35^{\circ} \mathrm{C}$. The presence of turbidity in broth cultures was adjusted according to $0.5 \mathrm{McF}$ arland standards by the addition of sterilized plain broth [16].

Standardized bacterial suspension was saturated with a sterile Dacron tip swab and excess culture was removed by turning the swab against the side of the tube. Inoculum was spread evenly over the entire surface of the Mueller-Hinton agar plates by swabbing back and forth across the agar in three directions to give a uniform inoculum to the entire surface. These plates were allowed to dry before applying discs and after 15 minutes discs of given potency were applied 
on the inoculated plates with the help of forceps. These plates were then placed in an incubator at $35 \pm 2{ }^{\circ} \mathrm{C}$ for 24 hours in inverted position. After 24 hours of incubation, plates were examined and the zone of inhibition was measured.

\section{Results and Discussion}

Antibiotic resistant bacteria pose a growing problem of concern, worldwide. Mastitis is the most common cause for antibiotic use in dairy herds. Effectiveness of current treatments and ability to control infectious diseases in both animals and humans may become hazardous. Out of 152 isolates of S.aureus, 82 (53.94\%) were resistant to one or more antimicrobial agents tested by this method. There was no resistant strain to gentamycin, whereas $63(41.44 \%), 39(25.65 \%)$, 21(13.81\%), $18(11.84 \%), 6(3.94 \%)$ and $5(3.28 \%)$ isolates for penicillin, streptomycin, erythromycin, tetracycline, ampicillin and Cephalothin, respectively (Table-1). Susceptibility of staphylococci isolated from bovine intramammory infections to selected antimicrobial agents has been already reported $[9,17,18]$.

Table-1. Antibiotic Sensitivity of Staphylococcus aureus strains $(n=152)$ from Subclinical isolates

\begin{tabular}{lcc}
\hline Antibiotic & No. of resistant & Percentage of resistant \\
\hline Penicillin & 63 & 41.44 \\
Streptomycin & 39 & 25.65 \\
Erythromycin & 21 & 13.81 \\
Tetracycline & 18 & 11.84 \\
Ampicillin & 6 & 3.94 \\
Cephalothin & 5 & 3.28 \\
Gentamicin & 0 & 0.00 \\
\hline
\end{tabular}

Sensitivity to penicillin predicts susceptibility to other $\beta$-lactam antimicrobial agents, e.g. ampicilline. In this study 152 (41.44\%) isolates of S.aureus were penicillin resistant. These results are similar to those reported from cows with mastitis in United States (44\%) [19], Argentina (40\%) [20] and Iran (57\%) [18] but higher than reported for S.aureus strains isolated from bovine mastitic milk in Germany (17\%) [3]. The detection of $\beta$-lactamase production in staphylococci is a useful and rapid method to detect penicillin resistance. At the National Veterinary Institute, Uppsala, $\beta$-lactamase results are used as rapid screen to indicate penicillin resistance [17]. For streptomycin our findings showed resistance to S.aureus (25.65\%), similar to the results reported by Saad Gooraninejad et al. [18] for S.aureus in Iran (30.62\%). The S.aureus was not gentamicin resistant. This result is similar to the results obtained for S.aureus in Iran (Saad
Gooraninejad et al., 2007) and Argentina (3.4\%) [20].

Erythromycin was included in the present study to evaluate the resistance against S.aureus. The results were similar to those reports from Iran [18] but lower than the results obtained from North Palestine (40.9\%) [7]. Present results regarding tetracycline resistance for S.aureus (11.84\%) were similar to those from Iran [18] but lower than the results obtained from North Palestine (45.5\%) [7]. In general our staphylococcal isolates showed high level of resistance particularly to penicillin, streptomycin, erythromycin and tetracycline which are commonly used in bovine mastitis treatment. Antimicrobial susceptibility patterns should be identified for staphylococci, as present susceptibility results indicate scope for selection of appropriate antibiotics which could be effective for successful treatments.

\section{Acknowledgements}

Authors are grateful to the University Grants Commission for giving financial support to the present investigation involved in a Major Research Project entitled "A Study of Ethno-Veterinary Medicinal Plants and in vitro antimicrobial activities against Bovine Mastitis isolated bacterial pathogens" [Sanction No. F. No. 35-121 / 2008 (SR) dt.20 March 2009] and also thankful to the Management and Administrative authorities of RVS Educational Trust for their encouragement and support.

\section{Competing interests} interests.

The authors declare that they have no competing

\section{References}

1. Sumathi B.R, Veeregowda B.M and Amitha R. Gomes, (2008). Prevalence and antibiogram profile of bacterial Isolates from clinical bovine mastitis. Vet.World. 1(8): 237-238.

2. Radostits OM, Gay CC, Blood DC, Hinchllif KW (2007). Mastitis. In: Veterinary Medicine 9th ed., Haracourt Ltd, London, pp. 174-758.

3. Tenhagen, B.A., G. Koster, J. Wallmann, W. Heuwieser, (2006). Prevalence of Mastitis Pathogens and Their Resistance Against Antimicrobial Agents in Dairy Cows in Brandenburg, Germany. J. Dairy Sci. 89:2542-2551.

4. Jian-ping Li, Hai-jian Zhou, Lin Yuan, Ting He, and Song-hua Hu, (2010). Prevalence, genetic diversity, and antimicrobial susceptibility profiles of Staphylococcus aureus isolated from bovine mastitis in Zhejiang Province, China. Journal of Zhejiang University Science B. 10(10): 753 -760.

5. Erskine, RJ and Wagner, S (2003). Mastitis therapy 
and pharmacology. Vet. Clin. North Am. Food Anim. Pract., 19: 109-138.

6. Kasravi, R., Bolourchi, M., Farzaneh, N., Seifi, H. A., Barin, A., Hovareshti, P. and Gharagozlou, F., (2010). Relationship between in vitro antimicrobial sensitivity of bovine subclinical mastitis isolates and treatment outcome in lactating dairy cows. Iranian Journal of Veterinary Research, Shiraz University, 11 (3): 249-254.

7. Ghaleb M. Adwan (2006). Antibiotic Resistance against Staphylococcal isolates recovered from subclinical mastitis in the North of Palestine. The Islamic University Journal, 14 (1): 1-9.

8. Twomey, D.P., A.I. Wheelcock, J. Flynn, W.J. Meaney, C. Hill, R.P.Ross (2000). Protection against Staphylococcus aureus mastitis in dairy cows using a bismuth-based teat seal containing the bacteriocin, lacticin 3147. J. Dairy Sci., 83: 1981-1988.

9. Moroni, P., F.Vellere, M.Antonini, G.Pisoni, G. Ruffo, S. Carli (2004). Antibiotic susceptibility of coagulase-negative staphylococci isolated from goats' milk. Int. J. Antimicrob. Agents, 23: 637-640.

10. Oliver S.P., M.J.Lewis, B.E. Gillespie, H.H. Dowlen, E.C.Jaenicke, R.K. Roberts (2003) - Prepartum antibiotic treatment of heifers: milk production, milk quality and economic benefit. J. Dairy Sci., 86: 1187-1193.

11. Gentilini E., G. Denamiel, P.Liorente, S. Godaly, M. Rebuelto, O. De Gregorio (2000). Antimicrobial susceptibility of Staphylococcus aureus isolated from bovine mastitis in Argentina. J. Dairy Sci. 83:12241227.

12. Barrow G.I., K.A. Feltham (1993) Cowan and Steel Manual for the Identification of Medical Bacteria. 3rd ed., Cambridge. 1993.
13. De Silva, Z.N., A.S. Cunha, M.C. Lins, L. Carneiro, A.C. Almeida, M.L. Queuro (2001). Isolation and serological identification of enteropathogenic Escherichia coli in pasteurized milk in Brazil. Rev. Saude publica. 35 (4):375-379.

14. Ellis, D.I., R. Goodacre (2006). Detection, identification, and enumeration methods for spoilage yeasts, p.28-54In Blackburn C deW (ed.), Food Spoilage organisms. CRC Press LLC.

15. Bauer, A.W., W.M.M. Kirby, J.C. Sherris, M.Truck (1966). Antibiotic susceptibility testing by standardized single disk method, Am. J. Clin. Pathol., 45, 493-496.

16. National Committee for Clinical Laboratory Standards. (1993). Performance standards for antimicrobial susceptibility tests for bacterial that grow aerobically. Approved standard M7-T2. $2^{\text {nd }}$ NCCLS. Villanova Pa.

17. Gianneechini, R.E., C. Concha, A.Franklin (2002) Antimicrobial Susceptibility of Udder Pathogens Isolated from Dairy Herds in the West Littoral Region of Uruguay. Acta Vet Scand. 43(1): 31-41.

18. Saad Gooraninejad, Masoud Ghorbanpoor and Amir Parviz Salati (2007). Antibiotic Susceptibility of Staphylococci Isolated from Bovine Subclinical Matitis. Pakistan Journal of Biological Science 10 (16): 2781-2783.

19. Bezek, D.M., (1998). Genus identification and antibiotic susceptibility patterns of bacterial isolated from cows with acute mastitis in a practice population. JAVMA. 212:404-406.

20. Gentilini E., G. Denamiel, A. Betancor, M. Rebuelto, M. Rodriguez Fermepin, R.A. De Torres (2002) Antimicrobial susceptibility of coagulase-negative staphylococci isolated from bovine mastitis in Argentina. J. Dairy Sci., 85: 1913-1917. 